\title{
Digital Tools and Instructional Rules: A study of how digital technologies become rooted in classroom procedures
}

\begin{abstract}
Summary
This paper examines how a classroom culture develops advanced strategies and procedures for handling complex digital tools. We report from a vocational Media and Communication course at an Upper Secondary School in Oslo, Norway. Our analysis reveals how a procedure called practical assignments has developed historically at the school, and how this procedure is carried out in the classroom. Theoretically, our study is informed by Activity Theory, which affords us tools to analyze how social institutions and learning trajectories evolve over time, and how longitudinal dimensions emerge in situ. Our findings show how teachers and learners create a space for solving context-specific problems involving sophisticated technology. A historical analysis is here crucial not only in understanding why digital technologies are used in specific ways, but also how they evolve into classroom conventions.
\end{abstract}

\section{Introduction}

This paper examines how a classroom culture develops advanced strategies and procedures for handling complex digital tools and how digital technologies challenge traditional positions of teachers and learners. The context of our study is a media and communication classroom where a teacher team has established consistent classroom procedures for using digital tools and how learners confront these procedures. The classroom we observed is a vocational Media and Communication course at an upper secondary school in Oslo, Norway (learners aged 17-18). One of the primary objectives of this course is to enable students to produce digital media such as film, photographs, audio, and websites.

Our empirical analysis highlights a specific classroom procedure called practical assignment, which is a task-based method developed by local course teachers to assess and test how learners handle digital tools. The course period we observed is a training phase prior to a web design project. The teacher's objective for this training phase is to prepare learners for using digital production software in web design. First, we analyze how practical assignments were introduced as a procedure to solve the problem of learners avoiding digital tools. Second, we analyze a specific situation in which a learner is struggling with an assignment and where the teacher and classroom conventions go against the initial purpose of the assignment - to help learners learn more about digital tools. We also show how student and teacher negotiations can be an important means of solving unusual problems and shortcomings in the classroom.

The data analyzed in this paper are taken from syllabus documents, instructional plans, 
and teacher interviews, as well as video-recorded classroom observations gathered during six weeks of field work. The historical analysis of practical assignments is based on document analysis of instructional plans, subject syllabi, assignment task sheets, and teacher interviews. Video-recorded conversational data are used to document a specific learner's approach to the practical assignment. Theoretically, this study is based on activity theory. Vital concepts in activity theory afford a theoretical understanding as well as an empirically informed analysis of how social practices and institutions evolve historically on the basis of inner tensions and contradictions. This framework helps explain the developments and/or transformations that occur when something new is introduced into practice. In this study, we trace the introduction of practical assignments as an institutional response to a persistent problem in classroom practice. We combine activity theoretical perspectives with the concepts of mastery and appropriation (Wertsch, 1998) in order to analyze the processes of agents (teachers and learners) that engage in practical assignments. From this dual approach we formulate two research questions:

- To what extent do practical assignments function as support for learning with digital tools?

- What positions do teachers and learner take when facing a complex problem in a technology-mediated practical assignment?

In order to answer these questions, we examine two time scales in the classroom: a) the established procedure's historical background and $b$ ) how this procedure reveals possibilities and restrictions in situational performance. Overall, our analysis aims to show how classroom procedures for using digital tools developed historically and how these preconditions are continually challenged by the situated dynamics in the classroom. The outcome of our analysis will be discussed in relation to issues that emerge when complex digital tools become institutionalized into educational practice. In this respect, it will be helpful to review some relevant research on the use of digital technologies in classrooms.

\section{Research on digital technology in classrooms}

A large body of research focuses on how digital technologies support learning in classrooms. One early but influential work is Schofield's study, "Computers and Classroom Culture" (1995). An interesting finding of Schofield's research is that the social organization of the classroom deeply affects how computers are used. She concludes that computers are "... social as well as technological objects, and their use is subject to the vagaries of the social milieu in which they are available for use" (p. 228). Schofield's research has been highly valued and recognized, and many subsequent studies have continued to address the importance of understanding the social dynamics involved in learning with technology (Littleton \& Light, 1999; Mercer \& Wegerif, 1999; Lipponen, 2001; Lund, 2004). However, most of this research seems to ignore the issue of how technology becomes an integrated part of classroom practice.

Larry Cuban applies a more critical perspective to technology in classrooms. His study, "Oversold and Underused; Computers in the Classroom" (2001), which is based on data from interviews, questionnaires, and classroom observations, concluded that neither schools nor teachers seem to change their educational practices when computer technology is introduced, even if these resources are readily available. Institutionalized educational practices do not budge easily.

Computer-supported collaborative learning (CSCL) is a research field that addresses 
the relation between technological development and the social aspects of learning by focusing on collaborative use of computers in classrooms. Relevant CSCL examples can be found in studies of how people learn by using software that promotes knowledge-building discourse (LeBaron, 2002; Suthers, 2005; Stahl, Koschmann, \& Suthers, 2007; Stahl \& Hesse, 2008). Quite a few CSCL studies document productive learning (Mercer \& Wegerif, 1999; Furberg \& Ludvigsen, 2007; Lipponen, Rahikainen, Lallimo, \& Hakkarainen, 2003), without romanticizing technologies.

However, in a review of CSCL research, Arnseth and Ludvigsen (2006) describe the field as generally covering short-term interventions and design studies. A main criticism in their review is that these studies fail to capture the long-term features of schools and classroom practices. These authors conclude that the main role of technology is a function of the historically developed practices within educational institutions. Their main argument is that research needs to examine how technologies are picked up and appropriated in practice over time.

In "Learning with Computers" (1999), Crook criticizes research for its failure to recognize the importance of the classroom community in which computer use is embedded. Several educators point to this problem as well, claiming that research on computers in classrooms tends to focus on the technology and not how teachers choose to use these resources in the classroom (Bitner \& Bitner, 2002; Lawless \& Pellegrino, 2007).

Price and Oliver (2007) confirm the limitations of research on technology-enhanced learning by emphasizing that the influence of technology on teaching and learning is studied primarily "in terms of novel or innovative initiatives-saying little or nothing about the impact of established technologies, or what happens when use of technology becomes "mainstream"' (p. 117). In conclusion, we find that a substantial body of research focuses on how technology affects learning. However, this research does not always provide us with the required insight into how teachers develop local strategies for their use of digital technology.

Media and Communication Studies, which is the empirical context of our study, is an educational setting in which digital technologies have become mainstream. Current research on media education explains that this trend is based on access to the low-priced digital software used in classroom-based media production (Livingstone, 2004; Sefton-Green, 1999; Frau-Meigs, 2003; Buckingham, 2005, 2003). According to Erstad, this use of digital technology has created new learning spaces in the classroom in Norwegian Media studies (2004, 2005). Erstad maintains that our knowledge about how these learning spaces are negotiated, constructed, and sustained is poorly documented in empirical research. Our analysis aims to make a contribution to this gap by looking closely at the relationship between the social and technological aspects of the Media and Communication classroom, and analyzing how technology historically emerged as an embedded social object in the classroom. The conceptual means we apply in this analysis are based on activity theory.

\section{Socio-historical and Situational Analysis of the Classroom Context}

Activity theory is a conceptual framework that aims to understand how local practices function and evolve in relation to a historical trajectory (Engeström, 1999a). An important principle in this theoretical scope is that material tools, symbolic entities, and human behavior together constitute social practices. Activity theory also presents human practices as a multi-leveled structure of operations, 


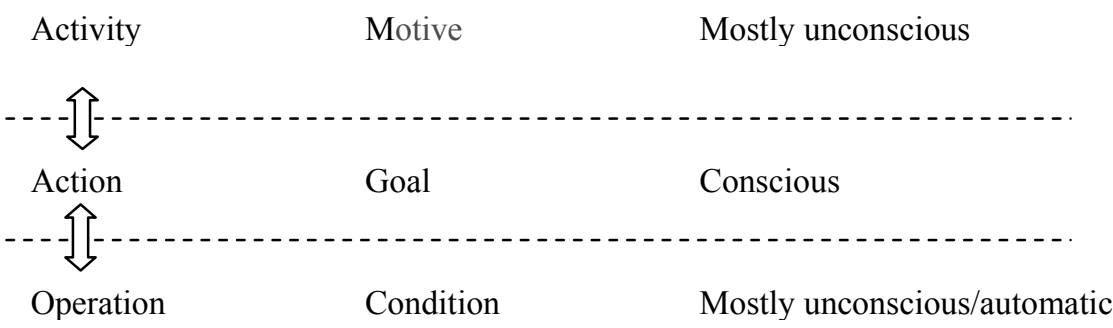

Figure 1. Three-level scheme of the structure of activity

actions, and activity. This structural description of activity was first presented by A. N. Leont'ev $(1978,1981)$. Activity is here defined as a historical trajectory of production, which comprises an object-oriented motive for sustaining an existing culture. Actions are goaloriented particularizations of an existing practice. Actions are related to this historical and object-oriented motive, but are distinguished from activity in that they are situated and goaloriented. Operations are the conditional means that are judged as appropriate in the process of achieving the goals. This three-fold structure is visualized in figure 1 above:

By introducing this tripartite structure, Leont'ev presents a distinction where actions/ operations have clear-cut beginnings and ends, while activity is historical and cyclical (Cole, 1996; Cole \& Engeström, 1993). Actions and operations connect to activity by regenerating patterns and customs at subordinate levels. Activity is here defined as object-oriented, in which the object is a collectively and historically constructed ideal.

The activity theoretical explanation of how social practices develop and change is based on the notion of contradiction. The notion of contradiction suggests that social practices are of a conflicting nature. Specific contradictions are here defined as opposing forces, which come to the surface as conflicts and tensions in practice (Engeström, 1999c). These inner contradictions are the moving energy of the activity and appear as deviations (e.g., when a tool does not serve its purpose or when participants disagree about the purpose of the activity). Resolving these contradictions is often the driving force behind transforming practices. Such efforts appear as improvements and adjustments to the rules, procedures, tools, or even the object of the activity.

The object of the activity determines a possible scope of actions. The object is represented in the material structure of the activity in the shape of concrete entities, as well as in the shape of symbols, concepts, and ideas. Foot (2002) explains how the object is collectively constructed:

\footnotetext{
The actors involved will share understandings about what they are doing and about what the relations among their activities, for example, that and why particular actions are appropriate responses to others. Their agreement, however, need only be partial. Participants in practice can have conflicting interpretations of it. Such conflict, however, occurs within a wider (although revisable) background of agreement concerning what the practice is ... (Foot, 2002, p. 13).
}

Consequently, actions relate to and make visible at least some part of the object. However, the totality of the object of activity can never be realized through momentary actions. To identify the object of an activity in research is therefore a demanding task. In order to re-construct the object, the researcher must therefore provide both situational and historical documentation. 


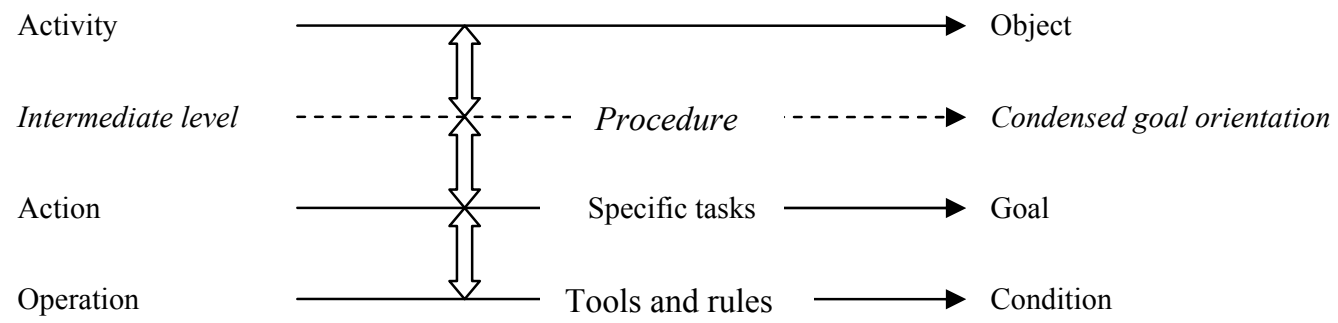

Figure 2. The hierarchy of activity, including an intermediary level of analysis

The theoretical framework outlined above affords an analysis of how motives, goals, and conditions are interrelated when people participate in social practices within institutional settings. In our study of practical assignments we focus on a classroom practice, an educational script, which is both historically grounded and situated in specific, goal-oriented actions. When we juxtapose these two dimensions, we often find an intermediate level between the collective activity and the individual action, as in Leont'ev's model (Figure 1) (i.e., subjects or groups engage in multiple or clustered actions). In his writing on innovation and project design, Hyysalo (2002, 2005) provides an interesting way to analyze these kinds of clustered actions in intermediate concepts:

(...) intermediate concepts are mostly members' categories, the emphasis being that they remain empirically grounded. At the same time these concepts are informed by key activity theoretical concepts: object, motive, subjects, community and signs (Hyysalo, 2005, p. 23).

Intermediate concepts allow the researcher to analyze empirically grounded descriptions. Hyysalo argues for this approach by stating that:

Had the activity theory concepts been applied directly, the possibility to reflect upon them would be lost, as the empirical case would be described already in the very terms it was further wanted to illuminate (ibid., p. 23).
Hence, empirically driven concepts circumvent analytic tautology. Hyysalo's study also discusses how the intermediary level of analysis can display coherent sequences or clusters of action. Hyysalo's point is illustrated in figure 2 above:

The main point in Hyysalo's proposal is that chained actions, such as we find in projects, clearly outlive the momentary scope of actions, but still only represent fragments of an activity. A similar argument is presented by Gonzales and Nardi in the unpublished paper, "Engagements: Understanding the instantiation of activities" (in preparation). In this paper, the authors describe the notion of connected actions as engagements that instantiate activity. They describe engagements as entailing “...chains of actions oriented toward the achievement of purposes that transcend the goals of individual actions" (ibid.). This notion of engagement is proposed as a transitional level within Leont'ev's threefold structure of activity:

\begin{tabular}{|l|l|l|}
\hline Activities & $\rightarrow$ & Objects \\
\hline Engagements & $\rightarrow$ & Purposes \\
\hline Actions & $\rightarrow$ & Goals \\
\hline Operations & $\rightarrow$ & Conditions \\
\hline
\end{tabular}

Figure 3. Modified hierarchy of activity

Gonzales and Nardi maintain that they want to preserve the original definitions of action as instances of conscious acts first presented by Leont'ev (1978). Kaptelinin and Nardi (2006) 


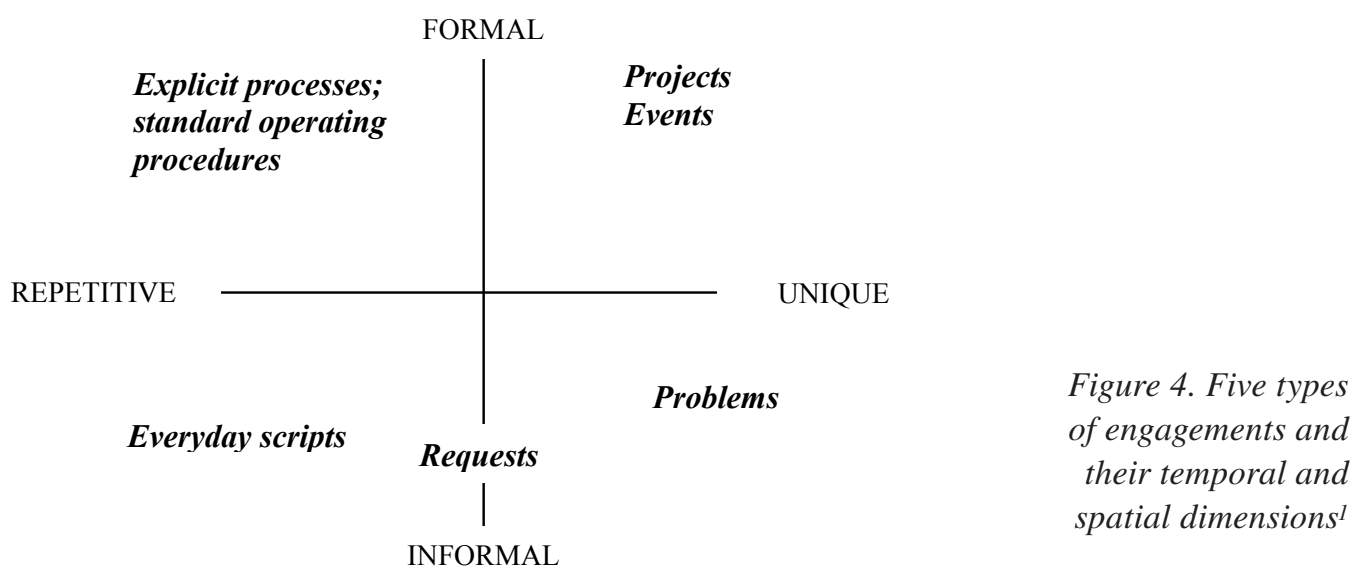

confirm that there is a need for conceptual elaboration to make patterns of action more approachable in empirical analysis. Compared to Hyysalo, Gonzales and Nardi seem to suggest a more theoretically anchored insertion of an intermediate level, i.e., engagements between goal-oriented actions and object-driven activity. According to Kaptelinin and Nardi (2006), this approach to an intermediate level can be defined as "chains of thematically connected actions oriented toward a particular purpose within a particular object-oriented activity" (p. 259). Similarly, Engeström (1999b) provides an interesting description of how an object is substantiated: “....situation-specific re-construction and instantiation of the object of an activity system often takes the form of problem finding and problem definition" (p. 381). Accordingly, problems, tensions, and conflicts that arise in practice, as well as how these issues are resolved, make the object visible. Problem solving enables people to better understand the object and what might be possible or plausible. If a problem reoccurs in practice, causing repeated irritation, the participants might search for a more reliable solution to the problem by establishing new routines or procedures.

The practical assignment as a classroom script resembles in many ways the notion of engagements conceived by Gonzales and
Nardi. On the one hand, it is an institutional routine or procedure executed in a cyclic and repetitive manner. Moreover, it reflects a possible solution to a recurring problem; the lack of commitment from all or most learners. In this sense it resembles an activity. On the other hand, it is structured into specific material instantiations with explicit exercises, tasks, and goals, executed within a limited time frame and reflecting only fragments of the object. In this sense it resembles the concept of action.

The above use of engagements has been criticized for being vague and imprecise (Rogers 2008). One critique is that Gonzales and Nardi seem to overlook how engagements are spatially and temporally embedded into social activity (Engeström 2008). Engeström therefore suggests that the notion of engagements needs to be specified in relation to when and how often they occur and to what extent they represent formal features or arise more informally. Such spatial and temporal dimensions are illustrated in the following model by Engeström:

Figure 4 above shows how Gonzales's and Nardi's notion of engagements revolves around distinct temporal and spatial features

1 In Engeström 2008, p 257. 
Teacher orientation

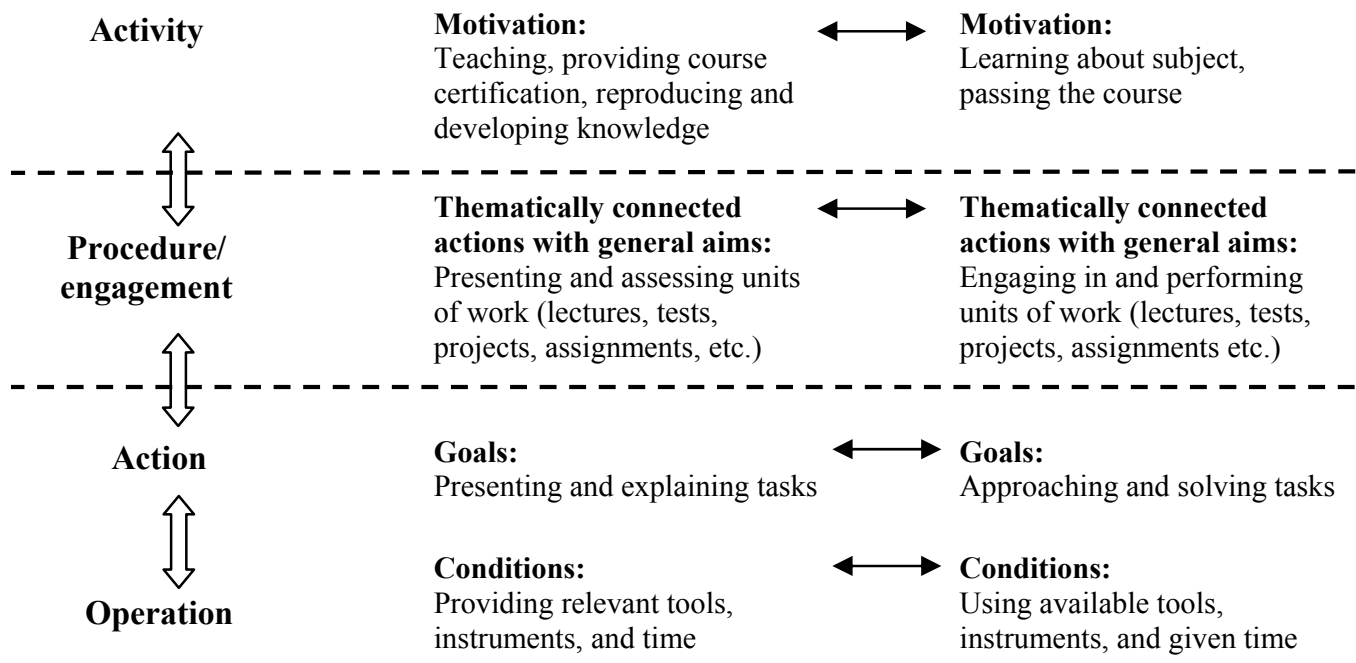

Figure 5. Practical assignment as a classroom engagement

(inspired by Gonzales \& Nardi; under preparation ${ }^{2}$ )

of an activity. Engeström's model allows us to distinguish between implicit and explicit features, as well as recurring or ad hoc engagements. Also, his spatial and temporal dimensions allow us to more accurately define the role of practical assignments as a formal and repetitive classroom procedure.

One challenge in our study is that classroom activity is different from the practices studied by Gonzales and Nardi and Hyysalo in that these authors analyze activities with a common object. In contrast, the media classroom is a context where learners and teachers are motivated by different objects. While the teacher is obligated to provide lessons, convey subject knowledge, tutor learners, and assess learners' performance, the learner is typically motivated by the object of passing the course and learning enough about the course subjects to obtain acceptable grades. This difference in motivations is not displayed in Hyysalo's intermediate level or in Gonzales's and Nardi's concept of engagements. The following model suggests how inconsistent motivational orientations can be included in the model:

Figure 5 (above) places engagements within an educational context and shows how learners and teachers approach classroom work from different positions and for different purposes. Engagements are here directed toward condensed general aims. General aims are an abstraction of the structure and purpose of the thematically connected actions. This means that, for example, when a teacher lectures on a topic, the separate actions during this process may convey different meanings when compared to the more cohesive and coherent purpose of the lecture.

We will apply the analytical model outlined above in our analysis in order to visualize how practical assignments constitute a current as well as historically grounded working unit in

2 Also with reference to Bedny \& Harries (2008); Souza (2008). 
the classroom. Our approach to this intermediate level is related to two empirical cases: 1) a historical account (documents, teacher interviews) of establishing the procedure and, 2 ) an in situ analysis of a learner enacting the procedure.

With its focus on media production, Media and Communication Studies involve a deep understanding and extensive use of digital tools by the agents involved in the practical assignment. Our theoretical approach to analyzing how tools are picked up and put to use draws on James Wertsch's (1998) view of the relationship between tool and person as an "irreducible tension between cultural tool and agent" (p. 30). With this view, understanding the use of software within the context of a classroom engagement is about unveiling the tension between the purpose and tool. We will do this by applying Wertsch's analytic distinction between mastery and appropriation.

Appropriation is a theoretical construct with dialogic and context-sensitive qualities. It has often been discussed and interpreted in theoretical studies (Rogoff, 1990; Säljö, 2000; Wertsch, 1998), but less often in studies that are more empirically grounded or that have didactic dimensions (for examples, see Grossman, Smagorinsky, \& Valencia, 1999; Lund, 2004, 2008).

Wertsch $(1998,2002)$ emphasizes the resistance found in appropriation, when a cultural tool is not appropriated smoothly but with friction or even conflict. This is an important issue to consider when we examine a situation in which a learner uses technology in a particular institutional context. Wertsch also discusses how the original purpose ascribed to the cultural tool may be transformed and redirected. The socio-historic context that gives rise to a particular use of the tool is therefore not static: "Mediated action is often organized around multiple, and often conflicting, goals, due to the fact that the goals of the agent do not map neatly onto the goals with which the mediat- ing means are typically associated" (Wertsch, 1998, p. 34).

Mastery of a cultural tool does not necessarily require personal commitment or emotional investment. Mastery can be exercised as control over tools; it is instrumental, unidirectional, and almost manipulative. Therefore, mastery is tactical and opportunistic, involving automatic skills. Appropriation requires more emotional involvement; it is a question of investing identity into the use of mediating tools. In the following, this understanding of appropriation and mastery will be pursued empirically through observations and analysis of how a practical assignment is executed in classroom practices that involve the use of media production software.

To summarize, this paper adopts an activity theoretical analysis at the intermediate level of classroom procedures/engagements. The analysis aims to show how teachers have constructed the didactic script of practical assignment in order to solve a historical contradiction in the media production classroom. Also, we analyze how a learner executes a specific assignment in which a series of situations reveals disturbances and tensions between how teachers and a learner orient themselves toward the classroom procedure. In the following selection, we describe the context of the study and some methodological considerations for our data selection.

\section{Methods and Context Description}

Our study reports from a second-year course in vocational Media and Communication Studies at "Longhill" Upper Secondary School in Oslo. We conducted the observations in spring of 2005. The school we observed has approximately 560 learners and a staff of about 70 . The learners in this course have access to a variety of digital technologies, such as video and still cameras and audio recording equipment. 
Each learner has his or her own computer with a broadband Internet connection and up-todate editing software for video, audio, and web productions. The role of digital technologies in this course is accentuated in several sections of the course syllabus:

The pupils should have knowledge about various production techniques for making stills and live images (...) use technology for electronic and printed publication (...) [become] familiar with areas of application for vector and bitmap graphics. (Ministry of Research and Education, 2001, pp. 9-12)

The above quotations provide a glimpse of the knowledge requirements related to digital technologies in Media and Communication Studies. Our empirical approach to this context is based on ethnographic classroom observations over a period of six weeks, covering a whole school project in web design. These classroom observations were videotaped, capturing both plenary events and students working individually and in groups. Additional data are documents, instructional plans, teacher conversations, and interviews as well as student productions carried out during the six weeks of observation.

The aim of our analysis is to examine how a classroom develops local scripts to face complex digital tools and how these scripts are challenged by situational dynamics. Ethnographic studies of classrooms commonly focus on student and teacher interactions (Mercer, Littleton, \& Wegerif, 2004; Crook 1999). A problem with approaching classroom scripts on the basis of interactional data is that these scripts are a familiar and shared part of the participants' experiences. This often removes the need to talk explicitly about the premises and purposes of ongoing events. The researcher's challenge in this respect is that he/she is not a part of this shared classroom reality (Crook 1999).

In order to capture these hidden features in the classroom, we have chosen to focus on disturbances in ordinary classroom work. Disturbances have the ability to bring about more explicit discussions on the premises and rules of classroom behavior. Our analysis of these disturbances led to our discovery of several formal and informal features in the classroom, including the formal procedure of practical assignments. In the following analysis, this empirically driven detection of practical assignments is divided into two separate but interconnected cases. The first case explores the historical contradiction that gave rise to practical assignments as a classroom procedure. The second case describes the problems a learner experienced carrying out a practical assignment.

A central aspect in our historical analysis is periodization, which means that we break historical events into chunks or patterns (Engeström, 1999b). These patterns tell us not only how an activity has evolved, but also how historical events influence moment-tomoment situations. The main data in the historical case is gleaned from local documents, teacher conversations, and interviews that help us draw a retrospective picture of how and why practical assignments were established. This first case mediates the institutional and temporal relationship between situational actions and historically evolving activity (Engeström, 1999b).

In the second case, we observe a learner carrying out an assignment. This case is selected because it shows through a series of episodes how the potential resolution is disturbed by constraints in the available artifacts as well as in the shifting subject positions of the participants (teachers and learner); the task simply cannot be solved with the existing version of the software, resulting in very different strategies for finishing the practical assignment. This tension, or even breakdown, allows us to analyze how the learner and teachers negotiate different ways of facing an unanticipated 
problem. Our analysis is built on transcribed interactional data (conversations, gestures, use of tools). By examining the participants' approaches, reasoning, and actions, we aim to uncover how they try to bridge the gaps that occur during the breakdown, and how these repairs relate to the history behind practical assignments.

The second case is documented in four hours of video recordings, which are broken into five sequences or episodes in the empirical analysis. These sequences are selected because they display tensions between the historically established routines and situationally involved agents. These episodes display the student's course of action, beginning at the discovery of a problem and ending at the finding of a solution. This case shows how the learner finds himself in a position where the affordances and constraints in the situation bring about an opportunity to transcend the traditional school script and teacher - learner orientations as illustrated in Figure 5 above. This visualizes how a situational tension in executing a task arises within the historical and systemic framework of the first case.

In sum, the second case is unique in the sense that it probes a contradiction that has historical roots but emerges in a particular shape at the juxtaposition of problem, tools and agents' positioning. On the other hand, we argue that it holds analytical generalization; i.e. "the extent to which findings from one study can be used as a guide to what might occur in another situation" (Kvale, 1996, p. 233). Thus, the particular tensions are not sought generalized in a strict sense but indicate what is possible or what might be given certain cultural-historical affordances.

\section{Case 1 - The History of Practical Assignments}

2003 was the first year for the Media and Communication course at Longhill Upper Second- ary School. The classroom activities for this first course year were mainly structured into project periods. The project periods were connected to specific media topics such as film, advertisement, web design, etc. These projects asked students to design diverse media representations, and then reflect theoretically on them on the basis of subject literature presented during the course. Project periods lasted from 4 to 6 weeks.

At this time, the teaching team did not provide formal training and exercises in digital production, and instead handed out software manuals and gave learners some time before the projects to run through the software. The use of digital tools was considered an integrated part of project work. The actual software training and production preparation were thus informally established as the concern and responsibility of the learners.

This informal practice brought about unanticipated results for the teaching team. The lack of preparatory digital groundwork resulted in a division of labor where already technically skilled learners took over the digital media production in the projects, while the rest of the learners took on other tasks such as writing the text to be used in the media productions and project reports. Since the course was mostly organized around project work and since the learners worked together in project groups, this internal division of labor evolved into an established classroom script amongst learners in this course. The result was an unanticipated practice in which a majority of the learners did not advance their skills in digital media production. Figure 6 (below) indicates teachers' and learners' orientations in this first course year:

The arrows in the model above signal the differing orientations between learners. A major conflict thus surfaced in the classroom, as the learners divided the work differently from what the teaching team expected and from 


$\begin{array}{lll}\begin{array}{l}\text { Media production in } \\ \text { Subject syllabus: }\end{array} & \text { I Teacher orientation } \\ & \text { Informal script: } \\ \text { The use of digital tools } & \text { I Production merged into media projects } \\ \text { in planning and } & \text { I - unspecified approach to digital } \\ \text { producing text, images, } & \text { I production } \\ \text { and audio products for } & \text { I } \\ \text { printed/electronic media } & \text { I General aim: } \\ & \text { I Teaching production on basis of whole } \\ & \text { I projects without specific instructions } \\ & \text { I for digital production }\end{array}$

\section{Student orientation}

\section{Informal script:}

$\longleftrightarrow$ Engaging with unspecified digital

production - informal division of labor, passing production tasks to skilled learners

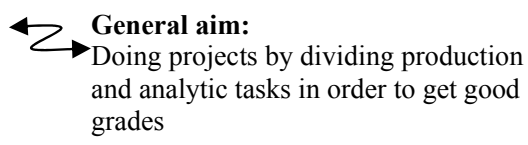

Figure 6. Teachers' and learners' orientation toward media production in 2003

what is required in the subject syllabus: that all learners should learn about and engage in digital media production.

So, on the one hand, the learners' own division of labor tended to rule out all but the skilled learners from media production. On the other hand, the teachers' lack of organized software training and relevant guidance failed to assist average and less skilled learners to engage in digital media production, essential objectives in media education. Consequently, the situation resulted in a contradiction. The teaching team responsible for establishing a subsequent advanced course in 2004 described the situation as follows:

Teacher 1: Those who started the course [in 2003] were very theoretical; all of them had a theoretical and academic background. And two of them had been working [academically] with media education, or they had a media science background. So, I think the focus was very much on design and communication theory and not so much on practical production training, which was left more to the learners (...). [The learners had] little training. Little training from the teachers, but this training was more independent.

The description given by Teacher 1 is confirmed by her colleague, Teacher 2, who describes the situation in 2003 as having a technically rough start:
Teacher 2: They started out a bit weak already then, because they did not really know what they were after. So, already in the beginning they received equipment which was out of date. So, the first course year started with below average equipment compared to the market, because they did not have anyone [in the team] with technical competence.

The two extracts above point to a low level of technical competence and a lack of focus on digital production and training in the basic course in 2003.

If we examine this situation through the lens of activity theory, we first need to identify the contradictory features in practices. As mentioned in the theoretical section, activity theory asserts that social practices are of a conflicting nature and that opposing forces surface as conflicts and tensions. The inner contradictions we find in this historical account are, on the one hand, between the media production syllabus goals and the teachers' obligation to facilitate the learners' engagement with digital production and, on the other hand, learners' orientation toward engaging mainly skilled learners in production. The learners' rationale might be found in the fact that this division of labor is conducive to project groups earning better grades in media production. Another reason for such division of labor might be found in the missing rule aspect of the activity (i.e., the lack of 
Table 1: Key features in practical assignments as a new procedure in 2004

\begin{tabular}{llll}
\hline $\begin{array}{l}\text { Problem } \\
\text { definition }\end{array}$ & $\begin{array}{l}\text { Conceptual } \\
\text { description }\end{array}$ & $\begin{array}{l}\text { Creation } \\
\text { of new procedure }\end{array}$ & $\begin{array}{l}\text { Consolidation } \\
\text { in practice }\end{array}$ \\
\hline $\begin{array}{l}\text { Lack of production cul- } \\
\text { ture/limited use of pro- } \\
\text { duction software in the } \\
\text { classroom }\end{array}$ & $\begin{array}{l}\text { Lack of practical train- } \\
\text { ing and exercises; frag- } \\
\text { mented participation in } \\
\text { digital production }\end{array}$ & $\begin{array}{l}\text { Tests/tasks in digital } \\
\text { production; grading } \\
\text { learner performances in } \\
\text { tests/tasks }\end{array}$ & $\begin{array}{l}\text { More dynamic pro- } \\
\text { duction culture in the } \\
\text { classroom involving all } \\
\text { learners }\end{array}$ \\
\hline
\end{tabular}

routines or directives for learner commitment in object-oriented endeavors).

The teachers interviewed demonstrate how they used the situation outlined above as an opportunity to develop a more production-oriented practice in their own classrooms. Teacher 1 , who moved on to become one of the teachers in charge of the following course in 2004, explained that the teacher's previous 2003 course experience “... automatically made us shape this (new) course with more focus on production." To promote and support digital media production that involved all learners, the teachers introduced training sessions prior to each project period as well as practical assignments and tests focusing on the use of digital tools. Such formalized and organized training was introduced in the fall of 2004, and has, according to Teachers 1 and 2, become an established component of classroom practices.

Practical assignments are the final tests, which usually take place at the end of each training session. These assignments require the execution of specific tasks that require the use of functions and production techniques. Practical assignments include tasks such as producing a visual shape, manipulating a picture, changing shades or colors, creating digital animations, editing films, etc. These assignments usually contain a combination of answerable questions and production tasks that are graded and counted toward part of the total course evaluation. Table 1 above displays the steps through which this procedure evolved and eventually established a new production culture in the classroom:
Table 1 (above) describes the process of problem definition to final implementation, where practical assignments eventually became a standard component of classroom practice. The purpose of introducing practical assignments was to motivate learners to actively take part in digital production, and to monitor the development of learners' skills. According to the teachers, these assignments seemed to engage the whole class more actively in systematic digital production. Grading the practical assignments also motivates the learners and formalizes the procedure, which encourages learners to invest more energy into learning the relevant technology prior to each project. These steps seemed to resolve the contradictive features experienced in 2003. Figure 7 (below) positions the practical assignment procedure on the intermediary level of engagements:

As figure 7 shows, practical assignments serve multiple goals and purposes, because they intend to force learners to engage more systematically with digital tools as wells as provide an opportunity for assessing learners' production skills. From an institutional perspective, the teachers have introduced a controlling device for engagement with digital tools and evaluation of production competence (which corresponds to general aims 1 and 2 in teacher orientation, cf. Figure 7). Also, it would seem that practical assignments resolved the tension between the teachers' obligation to be in control of the class and learners' collective engagement with given tasks. Finally, the practical assignments provided the teachers 
Activity ----- Motivations

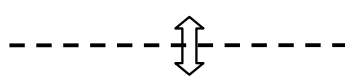

Practical assignment as classroom engagement

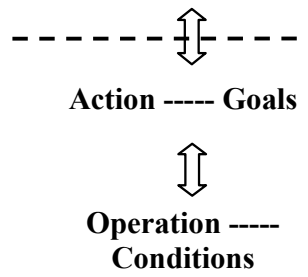

Teacher orientation

Motivation:
Teach about media; provide formal course certification; reproduce and develop knowledge

\section{Learner orientation}

Presenting thematically connected actions with general aims:

1. Monitor learners' production and classroom behavior

2. Assess production competence and skills
Motivation:

Learn about media;

pass the course

Figure 7. Practical assignment displayed as a classroom engagement with general aims

with an important overview of the challenges and problems learners experience in digital production, which informed their lectures and supervision before and during project work.

To conclude, this first case gives a historical account of how a classroom procedure was introduced in order to solve a problem, and how this solution became an integrated and recurring routine in the classroom that is reflected in instructional plans, worksheets, and exercises, and in the everyday vocabulary of learners and teachers. However, so far the notion of practical assignments has remained an abstract and analytic concept, a heuristic that serves to indicate or stimulate further investigation. Such abstract descriptions do not always map perfectly onto everyday performances. In the next section we examine how a student actually engages with a practical assignment.

\section{Case 2 - Negotiating a Practical Assignment}

Our second case examines a learner's engagement with one particular practical assignment, the aim of which is to evaluate learners' skills with the editing software Adobe Illustrator ${ }^{3}$. This assignment is divided into seven tasks, each requiring the use of a specific software function to produce a visual shape. Solving the tasks requires a set of practical skills considered important in electronic visual design. Our focus in this practical assignment is on task no. 7, which asks the learner to create a soda bottle label using vector graphics. We use excerpts from classroom conversations to describe the learner's efforts to complete the task shown below:

3 This application facilitates visual design in print or on the Web and is commonly used by professionals as well as in Vocational Media Studies in Norway. 


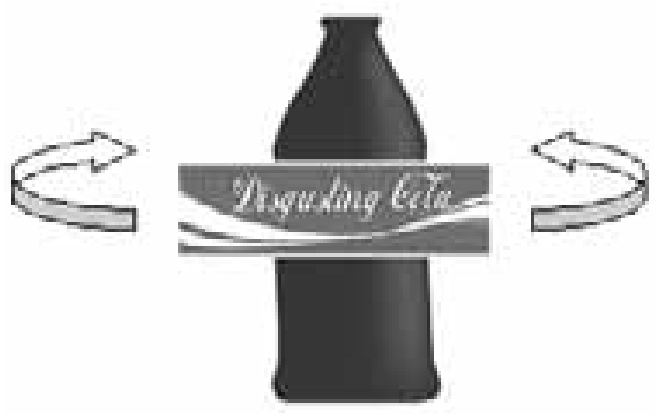

Figure 8. Task no. 7: fitting a label to a round bottle 4

Learner Mark has made several attempts to bend the label around the bottle as illustrated above. However, he has difficulty finding the correct software function. Mark seeks to solve this problem through discussions and negotiations with his fellow learners as well as several of the subject teachers. Mark repeatedly addresses a problem: that task no. 7 is impossible to solve due to software limitations. Figure 9 (below) gives an overview of the episodes in which Mark brings this to the attention of his classmates and teachers.

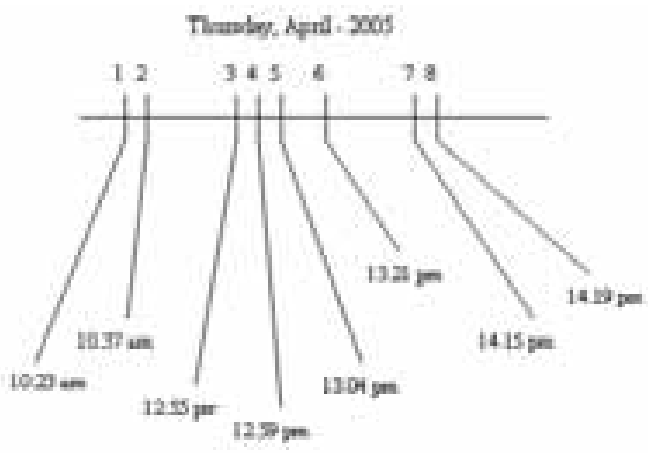

Figure 9. Overview of negotiations related to task no. 7 in the practical assignment. and gathered shortly after field work.
Sequence 1 in Figure 9 is a conversation between Mark and fellow learners, and sequences 2 through 8 are conversations between Mark and three different classroom teachers. From this set of conversational data, we have chosen to present sequences $2,4,5$, and 7 in addition to an introductory description of the first incident (see Figure 10, below). The circled sequences in the figure show the exact moment when the extracted conversations took place.

Thussdsy, Apnl - 2005

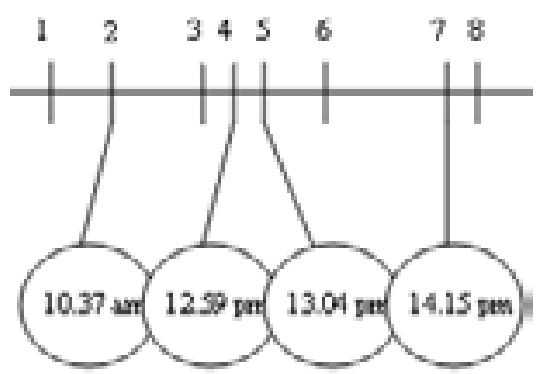

Figure 10. Overview of selected extracts

These sequences represent negotiations between Mark and his teachers about how to approach the problem. Before analyzing these extracts, we must provide an introductory description of sequence 1, which is the first visible initiative in the case.

Sequence 1 - First occurrence: discussion with fellow learners.

The first explicit appearance of the problem occurs at about 10:23 a.m. when Mark asks a fellow learner which software function will enable him to bend the "flat shape" of a label around the bottle as required in task no. 7. In general terms, this means that Mark needs to produce a curved shape from an originally flat image (see Figure 11 below): 

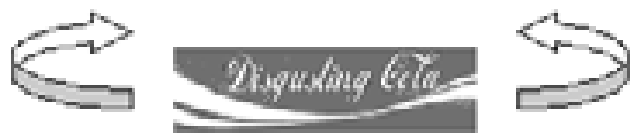

Figure 11. Task no. 7 in the assignment: bending the label around the bottle by using vector graphics

In order to do this, Mark must use vector graphics, which is a mathematical feature in design software that allows straight lines to be redefined as curved shapes. The problem, according to Mark, is that this particular feature is not available in this version of the software, which prevents the completion of this particular assignment. As a first response, Mark gradually involves several classmates. In picture 1 (below), we see one classmate standing next to Mark while Mark uses a soda bottle to describe the task and what the design software must do to produce the curved label shape.

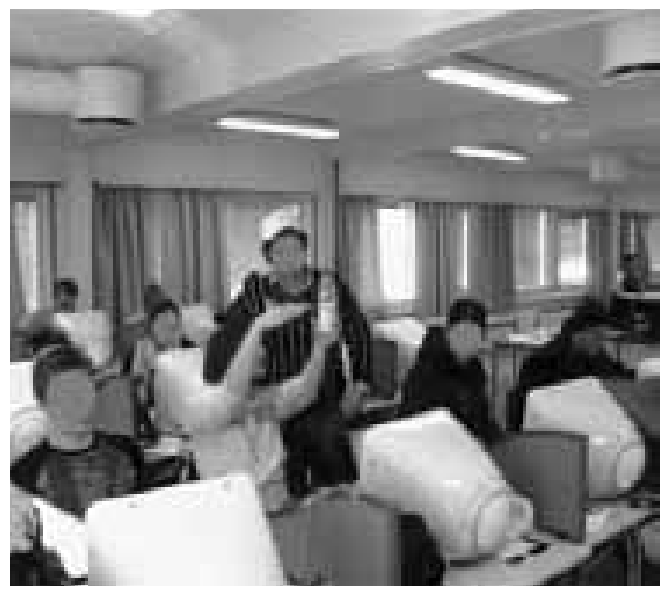

Picture 1. Mark describes the problem to a classmate (Sequence 1)

The classmate suggests an alternative approach, which is to brush a shadow onto the edges instead of bending the label, as shown in Figure 12, below:
Shatorre

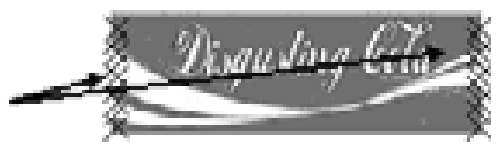

Figure 12. A fellow student's suggestion to shade each side instead of using vector graphics

Mark rejects this solution because it fails to accomplish task no. 7 as it is intended to be solved. The conversation in sequence 1 ends with Mark continuing to investigate the software menu in search for the vector graphics feature that will allow him to bend the label, an indication of increased tension between the task and the available tools.

\section{Sequence 2 - First teacher involvement.}

About 15 minutes later, Mark presents the same problem to Marie Howard, one of his teachers. The main difference is that he now goes beyond peer assistance to seek assistance from an authority figure that holds a teacher orientation toward the procedure of the practical assignment. Consequently, Mark addresses the problem in a tentative way:

1. Mark: Marie...

2. Ms. Howard: Yes.

3. M: ... a couple of questions. Do you know how (inaudible) with the tag on the bottle ... in the assignment?

4. H: ... I can't tell you (laughs) because it's a test (laughs again). It is an assignment, you know. None of the others did get any help, but they were allowed to use instr$\ldots$ all other sorts of means to be found in...

5. M: No, but I, uhm, it's likely that the assignment is incorrect, because, uhm, I don't think it's possible to do it in the way it is uhm...

6. H: But write it down as a comment so that it's, uhm, write down that it isn't... 
7. M: Yes, I'll talk to Mr. Christopher [another teacher, not present] about it.

8. H: Yes.

Line 3 in the extract above shows that, in the beginning, Mark addresses the problem by asking for help. The teacher rejects this request in line 4 by referring to classroom conventions and rules, in which teachers are not to help learners during practical assignments. In line 5, Mark suggests that the task cannot be solved given the available resources. The teacher's response in line 6 is that Mark should describe this problem in his paper instead of pursuing a practical solution. This is a deviation from the procedure. Mark responds with "Yes" in line 7 and that he is going to talk to Mr. Christopher, the teacher responsible for constructing the assignment. That he does not immediately agree to Ms. Howard's suggestion shows that he does not easily give up on pursuing a solution to the task at hand. In contrast, the teacher focuses on simply reporting the problem in writing, an approach that avoids investing time and effort into finding the strategy needed to solve the problem.

The sequence demonstrates how Mark is willing to invest his resources in task solution, and how he struggles to acknowledge and deal with the apparent mismatch between task and tool (see Lund \& Rasmussen, 2008 for an extended discussion). He is engaged in a process of appropriation. The teacher, on the other hand, enacts the institutional script of "doing school tasks" represented in her suggestion to avoid the problem, not to solve it or learn from it (lines 4 and 6). This would amount to a process of mastery of an institutional challenge without appropriation.

This conversation reveals how the two participants identify the problem differently. As a classroom procedure, practical assignments are employed to monitor learners and promote learning media production. What Mark points out is a breakdown between the constraints of the software tools and the solution required. Mark tries to bridge this gap by engaging the teacher in a discussion.

\section{Sequence 3 -Additional software information.}

Two hours later, Mark approaches Mr. Jacob, the second teacher involved in the lesson. This time, Mark presents the problem and offers additional information. The extract starts at the point where Mark offers Mr. Jacob a possible cause of the problem.

38. Mr. Jacob: Has it stagnated while you ... before you can use CS? [extended version of the software $\left.{ }^{5}\right]$

39. M: No, I'm trying to find a way, a different way to do it. But, uhm, I have read some on the Internet and...

40. J: ... it's only with CS...

41. M: Yes. I need an effect...

42. J: ... only with CS.

43. M: Yes, exactly. There are specific filters for doing those things in 3D. Warpf, is like uhm, is like ok enough, but I need a filter so that I can put in a perspective...

44. J: Hmm.

45. M: I have to, like this (points to the screen).

46. J: Yes...

47. M: ... and there is a specific filter called "Revolve" that does that (makes a curved gesture with his hands) that the edges are like (...) gradually declining (...), and, uhm, this effect is only in CS.

48. J: CS.

49. M: Yes, and, uhm, this effect is only in CS. I don't know when he [Mr. Christopher] prepared the assignment, if he ... what he had in mind. So I actually need to talk to him. I haven't been able to get hold of him the whole day.

5 Illustrator CS is a version that includes capabilities to extrude or revolve shapes to create simple threedimensional objects. 
50. J: Yes, I think you need to talk to him. Check if there... (...) is this the last thing you are supposed to do?

51. M: Yes ... yes-yes, I'm finished with all the other things.

The extract details Mark's explanation of the software's technical shortcomings for the task at hand. Mark explicitly refers to the Internet as an information source (line 39) and explains that he needs a particular software extension called Illustrator CS in order to solve the task. He wants to know what Mr. Christopher intended with this task (line 49) and, therefore, needs to get in touch with him. Mr. Jacob indicates that he understands the problem (line 38, 40, and 42) and agrees that Mark should get in touch with Mr. Christopher, but also asks if Mark has to do any other tasks (line 50).

This extract shows the learner making another attempt to resolve the problem by giving a technical and production-oriented account. Mark has rejected Ms. Howard's initial request in sequence 2 to report the problem in writing. Mark's technical explanations are now acknowledged by Mr. Jacob, who examines the situation in relation to whether Mark has done the other tasks required. In other words, the teacher signals that he is aware of the procedural elements of practical assignments while at the same time approving of Mark's technical and production-oriented approach to the task. Indirectly, Mr. Jacob acknowledges the tension in the engagement and an opportunity for exploiting it for learning.

\section{Sequence 4 - Disagreement.}

In the next sequence, about five minutes later, the situation changes when Mr. Jacob challenges Mark's technical and production-oriented approach:

52. Mr. Jacob: You just finish now. And then hand it in as it is now...

53. Mark: Yes.
54. J: ... and then you write a sentence or three ... as many sentences you need (...) in order to explain.

55. M: Yes, yes.

56. J: ... that uhm, uhm, "you stop there because you need this and that, "bladi-bla", $\ldots$ and so on.

57. M: Yes.

58. J: If you explain this with simple words, you know, then...

59. M: Yes.

60. J: ... it's as good as, uhm...

61. M: ...but, I might as well talk to him [Mr. Christopher] because I'm going to, uhm, I'm supposed to hand it to him personally anyway.

62. J: Are you?

63. M: I don't have access to any hand-in folder, [i.e., on the school's $\mathrm{LMS}^{6}$ ] so I might as well mention it to him then.

64. J: You are going to single it out and hand it over to him, then it ... or you can compose a comment-bubble on, uhm, you can...

65. M: Yes.

66. J: ... make a, uhm...

67. M: ... but, yes!

68. J: ... try to make something witty out of it.

In this sequence, Mr. Jacob stops Mark from pursuing a solution to the problem and urges him instead to explain why he cannot solve the task (lines 54, 56). The teacher's statement, that the written description is "as good as" (line 60), shows that his position is similar to that of Ms. Howard. Mark, on the other hand, is oriented toward getting to the core of the problem. The teacher's suggestion that Mark could make a comment-bubble (line 64) or "make something witty out of it" (line 68 ) reflects a more superficial attitude to the

6 A Web-based Learning Management System 
problem with an emphasis on finishing work. Mark continues to push for further discussion of the problem in lines 61 and 63 by offering to consult a third teacher instead of just handing in an online response.

The extract above demonstrates how Mark's position now is quite different from that of the teachers. The two teachers rephrase the task and adjust the goal toward a different purpose than in the initial task. It should also be noted that the problem has caused a substantial delay in Mark's progression, causing him to fall behind the rest of the class. The teachers seem to focus on minimizing this delay, while Mark persists in finding a solution. These different approaches-mastering the request for handing in a result and appropriating a strategy for actually solving the hitherto unmanageable task-continue in the last extract.

\section{Sequence 5 - The turning point.}

This last extract takes place approximately an hour later. It starts with Mr. Jacob repeating his request, now demanding that Mark finishes the assignment.

122. J: No, I thought that ... finish what you are doing now ...this assignment here, the Illustrator assignment.

123. M: Yes.

124. J: ... then you hand it over and get finished with it.

125. M: Yes.

126. J: ... and then you catch up with what...

127. M: Yes. I can do some work on Flash, but it has more synergy effect.

128. J: It does?

129. M: Yes.

130. J: Because there are things you are going to use in Flash?

131. M: To a degree, yes.

(Another learner interrupts the conversation; this lasts for about 20 seconds.)
132. J: Ok, then. You handle this on your own, you work with the assignment and what you intended to compose (inaudible).

133. M: Yes.

134. J: If you need to do things in Illustrator in order to make use of it in Flash, you can do so.

135. M: Yes, great.

In the extract above, the teacher first restates his position and tells Mark to hand in the assignment with a written description (lines 122, 126). The teacher then explicitly states that the learner has to "catch up" with the rest of the class (line 126) who are already engaged in a new task involving Adobe Flash software.

A major shift in this extract occurs when Mark states that "I can do some work on Flash, but it has more synergy effect" (line 127). In this utterance, the word "it" refers to solving the problem in the Illustrator assignment, while "synergy effect" suggests that solving the problem in the Illustrator assignment would be beneficial to the next assignment in Adobe Flash. Mark justifies his approach to this assignment by contending that it will save time through the "synergy effect," a response to the teacher's worries. Mark's utterance in line 127 therefore indicates that he is able to see how different tasks are related and how working on one can inform the solution of another. In this way he also responds to the teacher's concerns regarding both the learning and control aspects of practical assignments. This is picked up by Mr. Jacob in lines 128 and 130. After the interruption, Mr. Jacob shifts his position by allowing Mark more autonomy. Mark is now encouraged to pursue the problem by appropriating available resources and not just mastering the institutional context by handing in a description of the problem.

This second case has made visible how a breakdown in the practical assignment is followed by negotiations during which the participants refer to different aims and pri- 
orities. As we pointed out in our institutional analysis of case 1 , practical assignments have the two major aims of facilitating media production learning and monitoring learners in the classroom. The breakdown in the second case reveals that the learner strongly identifies with the production aspects, while the teachers identify with the monitoring aim.

Throughout the excerpts, we see how the participants position themselves in relation to the mastery and appropriation of an unexpected challenge. The mismatch between task and tool as well as the complex nature of the tools involved rattle the subject positions of the participants. Mark's intensive engagement demonstrates an emotional commitment to fulfilling the task, which involves developing new knowledge and not just reproducing given knowledge. This commitment goes beyond responding to the teachers' primary concerns, and is aimed instead at understanding the problem. This process can be traced through different stages. The interaction data reveal an evolving process that begins with Mark asking his peers for help. This process gradually evolves from what Mark, in the beginning, refers to as an "impossible" problem (sequence 2 , line 5), to a search for information and, at the end, to finding a technical solution that goes beyond the software resources initially made available. This commitment reflects Mark's engagement in relation to both handling the task and finding the appropriate production tool. Time constraints do not seem to worry Mark. We argue that this process amounts to a case of appropriation; where a cultural tool is made one's own through friction and resistance and despite conflicting goals.

The teachers, on the other hand, orient themselves toward mastery of the situation by focusing on the controlling and monitoring aspects of the procedure. Such a focus on mastery is reflected in the teachers' resistance to let Mark pursue the problem in depth. They seem reluctant to go beyond the institutional framework and seem to perceive practical assignments as institutional and regulating procedures. This is clearly illustrated by their emphasis on reformulating the assignment into a matter of simple reporting. The teachers also explicitly mention time constraints and concerns that Mark must catch up with the rest of the class.

\section{Discussion and Conclusions}

The first research question in this paper addresses to what extent practical assignments function as support for learning with digital tools. The historical analysis in our first case provides us with an answer: a practical assignment is a graded test and controlling device that aims to involve all learners in the class. Testing and evaluation constitute important structural elements in the educational system. This makes learners prioritize the assignments. They prepare for these tests by learning about the software and rehearsing production techniques. This has resulted in a change in how learners engage with digital technology in the classroom. A main characteristic of this change is not found in the technology itself but in how learners are expected to engage with digital tools (i.e., social organization). This finding is in line with Janet Schofield's (1995) work in which she describes computers as both social and technological objects. Our findings also support the assertion by Arnseth and Ludvigsen (2006) that technology is primarily a function of historically developed practices within educational institutions. Our historical analysis of the emergence of practical assignments supports this claim. This historical reconstruction gives a glimpse of what Price and Oliver (2007) regard as contexts in which "the use of technology has become 'mainstream"” (p. 17).

Our second research question addresses how teachers and learners position themselves when faced with a complex problem in 


\section{Teacher orientation}

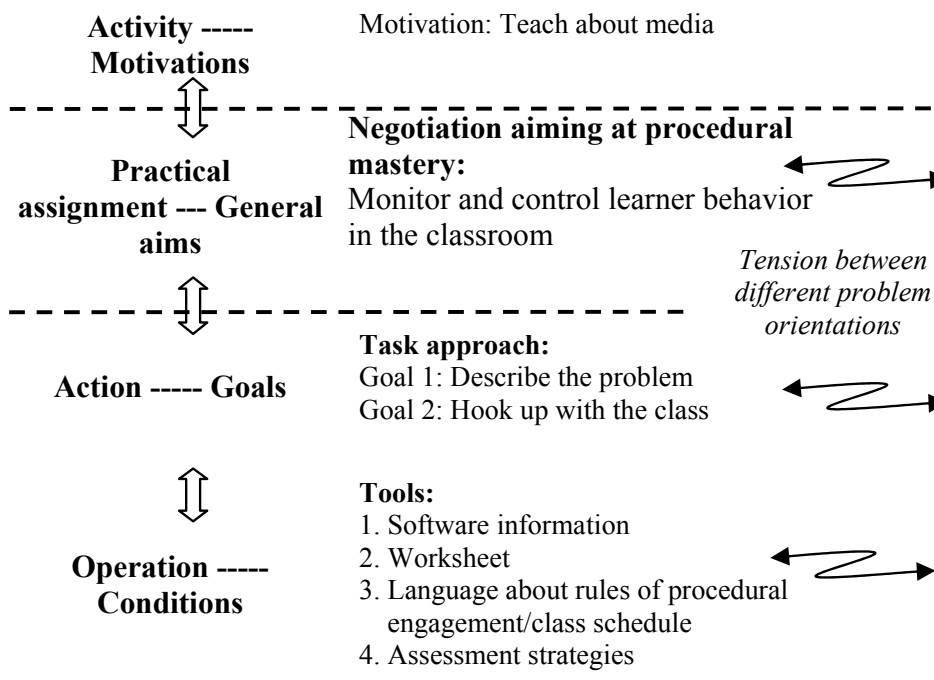

\section{Learner orientation}

Motivation: Learn about media aiming at production appropriation: Learn basic production skills and solve production problems

Task approach:

Goal 1: Solve the problem

Goal 2: Complete the production

Tools:

1. Software information

2. Worksheet

3. Language rules of procedural engagement in the classroom

4. Production/task strategies

Figure 13. Levels of activity applied to the second case

a technology-mediated practical assignment. Our answer to this question is related to the tensions documented in case 1 and how these were transformed, how they emerged, and how they were negotiated and partly resolved in case 2 . The social dynamics in the second case are highlighted by a breakdown that materializes as a conflict of goals and general orientation in the learner's and teachers' negotiations. A structure of activity that includes the intermediate level allows us to highlight this conflicting approach by applying the structure we used in Figure 7:

The model above lists the tensions in the practical assignment. These occur between goal 1 , which is to monitor and control learner behavior, and goal 2, which is to make students learn how to use digital tools. The breakdown becomes visible in the negotiations between learner and teachers. The teachers are responsible for monitoring progress and maintaining control. The learner is persistently trying to bend or even violate such regulations in order to accomplish the task. Analysis of their inter- actions reveals a significant emotional engagement in the participant's approach to the goals. In our analysis, we have used the concepts of mastery and appropriation to analyze different types of commitment and positioning. This analysis shows that doing practical assignments involves the mastery of procedural tools as well as digital tools. However, the real tension occurs when such mastery proves to be insufficient for a task that requires going beyond procedural and instrumental mastery. This affects the outcome of the situation. Our conclusion is that the control dimension of the practical assignment turned out to be an obstacle to the student's enthusiasm to learn.

However, it is important to acknowledge that the teachers eventually did allow the learner to pursue the problem. This last decision provides an important message about the social dynamics of the classroom. Major elements in this dynamic are: 1) that conventions create expectations; and 2) that broken expectations create tensions. What is special in our second case is how participants in a classroom turn a technical instrument into a 
social object. Another major finding in our second case is that changes in practice start with tensions, which open a space of opportunity in which participants can make adjustments or even create new conventions. However, in order to achieve substantial change, tensions need to be made visible and confronted. When tensions are confronted, we see a possibility to transform conventions and even practices. This is what our second case illustrates.

To understand technology as an embedded social object in the classroom requires us to pay attention to the social interactions that challenge or confirm conventions. These dynamics are constantly in play when teachers and learners engage in the classroom, and are vital to how they handle divergent requirements between curricular goals and social/situational demands. Such dynamics cannot be predefined by policy makers. These are local constructions that center on practical experience and problem solving in the classroom. In this sense, both the historical retrospect and the situational tensions show us how conventions involving digital tools are created in a local space and at a level between the collective activity and the individual action.

Our last point in this paper concerns the theoretical concepts and models used in the analysis. The intermediate level of analysis refers to aspects that are under-theorized in activity theory. The intermediate level is applied here as an extension of Leont'ev's original model. This extension is, of course, questionable as it has only tentatively been applied to empirical studies (Engeström, 2007; Rogers, 2007). Hyysalo $(2002,2005)$ put forward this intermediate level as a level for empirically driven concepts. In our case, this fourth level is included in the model as a middle ground between action and activity, which suggests a more theory-informed understanding of the concept presented by Gonzales (in Kaptelinin and Nardi, 2006). In this article, the intermediate level is applied as an analytic concept facilitating our empirical analysis. This level has proved to be helpful in unpacking the relation between situational actions and historical patterns in the classroom. Not only does it help explain established educational norms, but in empirical analysis, it also affords interesting perspectives regarding participants' different conceptions of the object of activity.

\section{Acknowledgements}

We thank both the learners and teachers at Longhill Upper Secondary School who kindly allowed us to observe their classroom activities. We also thank Sten Ludvigsen at InterMedia, University of Oslo, and two anonymous reviewers for their valuable comments on earlier versions of the manuscript.

\section{References}

Arnseth, H. C., \& Ludvigsen, S. (2006). Approaching institutional contexts: Systemic versus dialogic research in cscl. International Journal of Computer-Supported Collaborative Learning, 1(2), 167-185.

Bitner, N., \& Bitner, J. (2002). Integrating technology into the classroom: Eight keys to success. Journal of Technology and Teacher Education, 10(1), 95-100.

Buckingham, D. (2003). Media education. Literacy, learning and contemporary culture. Cambridge, UK: Polity Press.

Buckingham, D. (2005). The media literacy of children and young people - a review of the research literature on behalf of Ofcom. London: Centre for the Study of Children, Youth and Media. Institute of Education. University of London. London Knowledge Lab.

Cole, M. (1996). Cultural psychology: A once and future discipline. Cambridge, Massachusetts: Harvard University Press.

Cole, M., \& Engeström, Y. (1993). A culturalhistorical approach to distributed cognition. In G. Salomon (Ed.), Distributed cognitions: Psychological and educational considerations. Cambridge: Cambridge University Press.

Crook, C. (1999). Computers in the community of classrooms. In K. Littleton and P. Light (Eds.) 
Learning with Computers: Analysing productive interaction. London: Routledge.

Cuban, L. (2001). Oversold \& underused: Computers in the classroom. Cambridge, MA: Harvard University Press.

de Souza, C. S. (2008). Missing links in the rhetoric of Activity Theory. Interacting with Computers, 2(2008) 267-271.

Engeström, Y. (1987). Learning by expanding - an activity-theoretical approach to developmental research. Helsinki: Orienta-Konsultit Oy.

Engeström, Y. (1999a). Activity theory and individual and social transformation. In Y. Engeström, R. Miettinen, \& R. Punamäki (Eds.). Perspectives on activity theory (pp. 19-38). Cambridge: Cambridge University Press.

Engeström, Y. (1999b). Innovative learning in work teams. In Y. Engeström, R. Miettinen, \& R. Punamäki (Eds.), Perspectives on activity theory. Cambridge, New York: Cambridge University Press.

Engeström, Y. (1999c). Learning by expanding: Ten years after. Retrieved January 30, 2006, from http://carbon.cudenver.edu/ mryder/itc_ data/activity.html.

Engeström, Y. (2008). Enriching activity theory without shortcuts. Interacting with Computers, 2(2008) 256-259.

Erstad, O. (2004). Mediekompetanse i det soiokulturelle felt. Norsk medietidsskrift, nr 3(2004), 215-236.

Erstad, O. (2005). Digital kompetanse $i$ skolenen innføring. Oslo: Universitetsforlaget.

Erstad, O., Gilje, Ø., \& de Lange, T. (2007). Morgendagens medieprodusenter. Oslo: Det utdanningsvitenskapelige fakultet, Universitetet i Oslo.

Erstad, O., Gilje, Ø., \& de Lange, T. (2007). Redefining media learning - multiliteracies and digital production in Norwegian media education. Learning, Media and Technology, 32(2), 183-198.

Foot, K. (2002). Pursuing an evolving object: A case study in object formation and identification. Mind, Culture and Activity, 9(2), 132-149.

Frau-Meigs, D. (2003). Media regulation, self-regulation and education: Debunking some myths and retooling some working paradigms. In C. Von Feilizen, \& U. Carlsson (Eds.), Promote or protect? Perspectives on media literacy and media regulations (Vol. Yearbook 2003). Göteborg: The International Clearinghouse on Children, Youth and MediaNordicom.

Furberg, A., \& Ludvigsen, S. (2008). Students' meaning making of socioscientific issues in computer mediated setting: Exploring learning through interaction trajectories. International Journal of Science Education, in press, 1-25.

Gonzales, V., \& Nardi B. (in progress). Engagements: Understanding the instantiation of activities. Manuscript Draft.

Grossman, P. L., Smagorinsky, P., \& Valencia, S. (1999). Appropriating tools for teaching English: A theoretical framework on learning to teach. American Journal of Education, 108(November 1999), 1-29.

Hyysalo, S. (2002). Transforming the object in product design. Outlines, Critical Social Studies, 4(1), 59-83.

Hyysalo, S. (2005). Objects and motives in a product design process. Mind, Culture and Activity, 12(1), 19-36.

Kaptelinin, V., \& Nardi, B. (2006). Acting with technology. Activity theory and interaction design. Cambridge, Massachusetts: The MIT Press.

Kvale, S. (1996). InterViews. Thousand Oaks, CA: SAGE.

Lawless, A. K., \& Pellegrino, J. W. (2007). Professional development in integrating technology into teaching and learning: Knowns, unknowns and ways to pursue better questions and answers. Review of Educational Research, 77(4), 575-614.

Leont'ev, A. N. (1978). Activity, consciousness and personality. Englewood Cliffs: Prentice Hall. Retrieved January $6^{\text {th }}$, 2006, from http://209.85.129.132/search?q=cache: iD7wb1vpz W4J: www.marxists.org/archive/ leontev/works /1978/index.htm+Leont\%27ev $+(1978) \& h \mathrm{l}=$ no\&ct $=\mathrm{clnk} \& \mathrm{~cd}=2 \& \mathrm{gl}=$ no.

Leont'ev, A. N. (1981). The problem of activity in psychology. In James V. Wertsch (Ed). The concept of activity in Soviet psychology. New York: M. E. Sharpe.

Lipponen, L. (2001). Computer-supported collaborative learning: From promises to reality (No. 245). Turku: Department of Education. 
Lipponen, L., Rahikainen, M., Lallimo, J., \& Hakkarainen, K. (2003). Patterns of participation and discourse in elementary students' computer-supported collaborative learning. Learning and Instruction, 13(5), 487-509.

Livingstone, S. (2004). Media literacy and the challenge of new information and communication technologies. The Communication Review, 7, 3-14.

Lund, A. (2004). The teacher as interface - teachers of EFL in ICT rich environments: Benefits, practices, appropriation. University of Oslo.

Lund, A. (2008). Assessment made visible: Individual and collective practices. Mind, Culture and Activity, 15(1), 1-20.

Lund, A., \& Rasmussen, I. (2008). The right tool for the wrong task? Match and mismatch between first and second stimulus in double stimulation. International Journal of Computer-Supported Collaborative Learning, 3(4), 25-51.

McDonald, G., Le, H., Higgins, J., \& Podmore, V. (2005). Artifacts, tools, and classrooms. Mind, Culture and Activity, 12(2), 113-127.

Mercer, N., \& Wegerif, R. (Eds.). (1999). Is "exploratory talk" productive talk? London: Routledge."

Mercer, N., Littleton, K., \& Wegerif, R. (2004). Methods for studying the processes of interaction and collaborative activity in computerbased educational activities. Technology, Pedagogy and Education, 13(2), 195-212.

Ministry of Research and Education. (2001). Subject syllabus for upper secondary education - the media and communication area of study specialized subjects - advanced course 1. Oslo: White paper series.

Price, S., \& Oliver, M. (2007). A framework for conceptualising the impact of technology on teaching and learning. Educational Technology \& Society, 10(1), 16-27.

Rogers, Y. (2008). Varieties of Activity Theory. Interacting with Computers, 2(2008), 247-250.

Rogoff, B. (1990). Apprenticeship in thinking: Cognitive development in social context. New York and Oxford: Oxford University Press.

Schofield, J. W. (1995). Computers and classroom culture. Cambridge: Cambridge University Press.
Sefton-Green, J. (Ed.). (1999). Young people, creativity and new technologies: The challenge of digital arts. London: Sage.

Säljö, R. (2000). Lärandet i praktiken. Ett sociokulturellt perspektiv. [Learning in practice: A sociocultural perspective]. Stockholm: Prisma.

Stahl, G., \& Hesse, F. (2008). Explorations of participation in discourse. International Journal of Computer-supported Collaborative Learning (ijCSCL), 3(3), 1-2.

Stahl, G., Koschmann, T., \& Suthers, D. (2006). Computer-supported collaborative learning: An historical perspective. In R. K. Sawyer (Ed.), Cambridge handbook of the learning sciences (pp. 409-426). Cambridge, UK: Cambridge University Press.

von Feilizen, C., \& Carlsson, U. (Eds.). (2003). Promote or protect? Perspectives on media literacy and media regulations. Göteborg: The International Clearinghouse on Children, Youth and Media. Nordicom.

Wertsch, J. V. (1998). Mind as action. New York and Oxford: Oxford University Press.

Wertsch, J. V. (2002). Voices of collective remembering. Washington University, St. Louis: Cambridge University Press. 